Arhe XVII, 34/2020

UDK 16 Tarski A.

DOI https://doi.org/10.19090/arhe.2020.34.27-45

Originalni naučni rad

Original Scientific Article

\author{
UNA POPOVIĆ 1 \\ Univerzitet u Novom Sadu, Filozofski fakultet
}

\title{
SEMANTIČKA TEORIJA ISTINE ALFREDA TARSKOG
}

Sažetak: U ovom radu predstavićemo semantičku teoriju istine Alfreda Tarskog, kao odgovor na pitanje odnosa formalno-sintaksičkog karaktera savremene logike i mogućnosti njene primene na prirodne jezike, odnosno kao odgovor na problem logičkog karaktera prirodnih jezika. Semantičku teoriju istine Tarskog razmotrićemo na pozadini preosmišljavanja smisla i uloge pojma istine $u$ okvirima razvoja savremene logike, što u drugoj fazi tog razvoja vodi sve većem primatu pojma dokazivosti, na uštrb pojma istine. Sa druge strane, analizom stavova Tarskog pokazaćemo i da je semantička teorija istine bila izgrađena $\mathrm{u}$ dosluhu sa problemima paradoksa koji su obeležili razvoj savremene logike.

Ključne reči: Alfred Tarski, semantička teorija istine, objekt-jezik, meta-jezik, paradoksi

Semantička teorija istine Alfreda Tarskog (Alfred Tarski) predstavlja jednu od ključnih tačaka razvoja savremene logike. U pitanju je osoben zaokret kako u pogledu razmatranja za logiku tradicionalno ključnog pojma istine, tako i u pogledu opšteg smisla i dometa savremene logike. U tom smislu, ova teorija nezaobilazni je aspekt njenog daljeg razvoja, te je veoma uticala i na savremenu transformaciju modalne $\mathrm{i}$ temporalne logike, to jest, neklasičnih logika uopšte. Istovremeno, ona predstavlja razrađeni i promišljeni odgovor na pitanje usklađivanja dve naizgled suprotstavljene tendencije savremene logike: sa jedne strane, njen strogo formalni i simbolički karakter, a sa druge, tezu da se ona

\footnotetext{
${ }^{1}$ E-mail adresa autorke: unapopovic@ff.uns.ac.rs
} 
može upotrebiti za analizu iskaza prirodnog jezika, a posebno iskaza nauka, iskovanih upravo u tom jeziku.

Kao predstavnik druge faze razvoja savremene logike, Tarski nam obezbeđuje da, polazeći od njegovih doprinosa, iste sagledamo i spram onog što im je prethodilo, i spram onoga što su provocirali i što je usledilo nakon njih. Ta mogućnost biće rukovodeća i za nas u ovom radu: naš cilj je da semantičku teoriju istine Tarskog predstavimo na pozadini razvoja savremene logike, pre svega s obzirom na pomenuti zaokret $\mathrm{u}$ pogledu statusa $\mathrm{i}$ uloge pojma istine koji je ona u datim okvirima ostvarila.

\section{PROBLEM ISTINE U OKVIRIMA SAVREMENE LOGIKE}

Kao što je već pomenuto, problem istine predstavlja klasični i centralni problem logike još od njenih antičkih početaka. U izvesnoj meri, isto bi se moglo reći i za savremenu logiku, za čijeg se osnivača obično uzima Gotlob Frege (Gottlob Frege). Ipak, savremena logika, koja se zbog svoje neraskidive veze sa matematikom često naziva $i$ matematičkom ili matematizovanom, izgrađena je na osnovama sasvim različitim od one tradicionalne, te se stoga može očekivati da će i uloga pojma istine u njenim okvirima biti izmenjena.

Naime, osnovni poligon tradicionalne logike predstavlja horizont jezika, koji bitno obeležava njene početke u antici, kao i njen dalji razvoj u srednjem veku. U doba novovekovlja, primat jezika smenjuje primat mišljenja (ideja i njihovih odnosa), koji potom sve do savremenosti predstavlja pozadinu razumevanja smisla logike kao nauke o opštim formama valjanog rezonovanja i zaključivanja. $U$ datim okvirima istina je tipično vezana za pitanje iskaza (odnosno suda i suđenja), a sekundarno i za pitanje zaključivanja, ukoliko se radi o njegovoj primeni u naukama, odnosno ne o njegovoj formalnoj strukturi. Istina je, dakle, osobina iskaza/sudova, budući da tek oni imaju asertorički karakter - nešto tvrde ili poriču u pogledu stvarnosti. Za razliku od iskaza/sudova, osnovni elementi logičkog mišljenja - termini (pojmovi) - ne mogu biti ni istiniti ni neistiniti: kako to tvrdi još Aristotel, logička funkcija termina je da označavaju bića u stvarnosti, te se utoliko povodom njih ne može 
postaviti pitanje istinitosti. ${ }^{2}$ Drugačije rečeno, postaviti pitanje da li je reč „kuća” istinita ili ne naprosto nema smisla, ali je smisleno razmotriti da li je tvrđenje „Kuća je bela” istinito ili ne.

Kao što se može videti iz navedenog, ovakva logička pozicija problema istine je u tradiciji podrazumevala i različite varijante teorije istine kao korespondencije (sa stvarnošću); verovatno najpoznatija od njih je koncepcija istine kao adequatio rei et intellectus. Naime, pošto istinu vezujemo za iskaze/sudove, koji podrazumevaju da duh izvršava radnju spajanja ili razdvajanja dva termina, tipično postavljenih na pozicije subjekta i predikata, te da se takvim spajanjem ili razdvajanjem termina nešto tvrdi ili poriče o stvarnosti, sasvim je prirodno zaključiti da konačna odluka o tome da li je neki iskaz/sud istinit ili ne zavisi od toga da li ono što se njim tvrdi ili poriče na delu zaista jeste ili nije slučaj. Shodno tome, Aristotel kaže: „Tvrditi da nije ono što jest ili da jeste ono što nije jest lažno, a tvrditi da jest ono što jest ili da nije ono što nije istinito je, tako da onaj koji tvrdi da /nešto/ jest ili da nije mora ili govoriti istinu ili lagati. Ali, niti se za ono što jest kaže da nije ili da jest, niti se to kaže za ono što nije". ${ }^{3}$

Opisana perspektiva razumevanja logičkog statusa istine, međutim, nije primenljiva u okvirima savremene logike. Naime, savremena logika započinje jasnim otklonom od bar dve tradicionalne pretpostavke. Prva od njih je pretpostavka da je osnovni element logičkog mišljenja termin/pojam, koju u savremenoj logici smenjuje teza o logičkom primatu iskaza, pri čemu se termini sagledavaju kao sastavni i istinosno-funkcionalni deo iskaza. Potom je $u$ pitanje dovedena $\mathrm{i}$ pretpostavka da se logika tiče opisa načina na koji se de facto misli ili opisa načina na koji bi trebalo (ispravno) misliti. Već osnivač logike, Frege, napušta ove tradicionalne pozicije i, pod zastavom borbe protiv psihologizma, izgradnju logike vezuje za matematiku, te je u konačnom razume kao najapstraktniju formalnu nauku, koja stoji u osnovi svih drugih (formalnih i neformalnih nauka).

\footnotetext{
${ }^{2}$ Up. Aristotel, Organon, Kultura, Beograd, 1965, str. 53.

${ }^{3}$ Metafizika (1011b25); vidi u: Aristotel, Metafizika, Paideia, Beograd, 2007, str. 141-142.
} 
Fregeov logicizam brzo je doveden u pitanje od strane Rasela (Bertrand Russel), koji je savremenu logiku još jednom radikalno transformisao na samim njenim počecima, ostavljajući svim tadašnjim logičarima i matematičarima $\mathrm{u}$ amanet problem svog čuvenog paradoksa. I sam zastupnik logicizma, Rasel je ipak ovu radikalnu transformaciju izveo na fregeanskim osnovama, zadržavajući osnovni smisao Fregeovog logičkog poduhvata, uprkos neprihvatanju pojedinih Fregeovih postavki. Isto bi se moglo reći i za Hilberta (David Hilbert), kao i za druge značajne logičare savremenosti, uprkos tome što je dalji razvoj savremene logike doneo skoro bezbrojne njene transformacije i preobličavanja.

Fregeanska osnova savremene logike, nasuprot novovekovnim tezama, u centar logike vratila je primat jezika - sada, međutim, veštačkog (logičkog), a ne prirodnog jezika. ${ }^{4} \mathrm{U}$ tom smislu savremena logika postavljena je u okvirima izgradnje formalnih sistema, čiji su konstitutivni delovi formalni jezik (simboli i pravila formacije) i pravila transformacije (pravila koja određuju dopuštene oblike povezivanja iskaza). Rezultat su logičke formacije čiji elementi, kao ni njihove kombinacije, nemaju nikakve neposredne veze sa značenjima karakterističnim za reči prirodnih jezika ili sa mentalnim sadržajima empirijskog karaktera. Navedeno, međutim, znači i to da formalni sistem, kao osnova bilo kog logičkog istraživanja, nema nikakve neposredne veze sa opisivanjem stanja stvari u realnom svetu, pa, shodno tome, iskazi formalnih sistema nisu nikakva tvrđenja ili poricanja $u$ tradicionalnom smislu reči. Ovi iskazi potpuno su simbolički, formalni i lišeni sadržaja: ukoliko, na primer, razmatramo iskaz poput $p \Rightarrow \neg(q \wedge r)$ i pitamo o njegovoj istinitosti, na osnovu datog teško je uvideti kako bi se on mogao uporediti sa nekim stanjem stvari u realnosti i spram njega sameriti - odnosno, sa kojim stanjem stvari bi ga uopšte trebalo dovesti u vezu.

\footnotetext{
${ }^{4}$ Up. Дошен, К., Основна логика, 2013, str. 11. Elektronsko izdanje, slobodno na internetu: http://www.mi.sanu.ac.rs/ kosta/Osnovna\%20logika.pdf (datum pristupa: 29.06.2020.)
} 
Očigledno je, dakle, da tradicionalne teze o istini kao korespondenciji u ovim okvirima ne mogu da važe, te da se stoga može očekivati i da pojam istine, ukoliko ga uopšte u ovom kontekstu zadržavamo, mora promeniti svoj smisao i funkciju. To i jeste slučaj: u formalnom sistemu pitanje istine nekog iskaza/formule zapravo je pitanje logičke vrednosti datog iskaza/formule, a ona se određuje na osnovu niza parametara zadatih postavkom formalnog sistema. U tim okvirima ,istinito” (T, 1) i ,neistinito” $(\perp, 0)$ jedine su logičke vrednosti (ukoliko se ne radi o polivalentnim logikama); kao takvi, ovi izrazi svoj smisao zadobijaju samo unutar okvira datog formalnog sistema, te ne referiraju van njih. ${ }^{5}$

Ovako formalno postavljena logička obrada problema istine $\mathrm{u}$ savremenosti imala je, naravno, i svoje više sadržinske dopune. Tako je sam Frege, u skladu sa osnovnim tezama svog logicizma i postavkom prema kojoj logika predstavlja poslednji temelj svih ostalih nauka, smatrao da je formalni sistem zapravo otvoreni jezik - okvir otvoren za interpretaciju sadržajima bilo koje od nauka, koje bi takvom interpretacijom zadržale svoj pojmovnik empirijskog sadržaja, a zadobile strogu naučnu formu. ${ }^{6}$ Međutim, uprkos tome, uže logički smisao pojma istine ostao je rezervisan za prethodno opisani njen formalni karakter, a posledica toga bilo je i postepeno, ali sve više naglašeno pomeranje fokusa sa pojma istine ka više formalnom pojmu dokazivanja (dokazivosti). Navedeno je očigledno upravo u periodu prelaza sa perioda zasnivanja savremene logike na njenu drugu fazu, kako smo je prethodno označili: iako vidljiv i u okvirima intuicioznima, kao i kod Gencena

\footnotetext{
${ }^{5}$ Navedeno važi i za Tarskog, iako se on protivi Fregeovom stanovištu da su istinosne vrednosti individue; štaviše, čini se da Tarski smatra da je dodeljivanje istinosnih vrednosti nešto sasvim različito od bilo kakvog denotiranja. Up. Simons, P., 'Bolzano, Tarski and the Limits of Logic', in: Philosophy and Logic in Central Europe from Bolzano to Tarski. Selected Essays, Springer, Dordrecht, 1992, str. 25.

${ }^{6}$ Štaviše, Frege je komentarisao da je pojam istine izlišan, jer nam tvrđenje da je neki iskaz istinit ne govori ništa više od samog tog iskaza; navedeno se, naravno, odnosi na nov kontekst u kom se zatiče logički pojam istine. Up. McGee, V., Truth, Vagueness, and Paradox: An Essay on the Logic of Truth, Hackett Publishing, Indianapolis, 1990, str. 80.
} 
(Gerhard Gentzen), možda su najznačajniji primer takvog pomeranja Gedelove (Kurt Gödel) teoreme o nepotpunosti (nekompletnosti) i njima imanentno razdvajanje pojmova istinitosti i dokazivosti, u korist ove druge.

Semantička teorija istine Tarskog pojavljuje se upravo u ovom kontekstu, i to kao teorija koja, bar na prvi pogled, ima za cilj da u fokus savremene logike vrati kako sam pojam istine, tako i njegovu vezu sa iskazima prirodnih jezika. Taj zadatak, međutim, Tarski neće sprovesti odbacivanjem tekovina dotadašnjeg razvoja savremene logike, već, upravo suprotno, unutar njenih okvira. Na taj način, kako ćemo videti, Tarski je savremenu logiku imanentno otvorio ka do tada zatvorenim horizontima njenog daljeg razvoja.

\section{OSNOVNE CRTE SEMANTIČKE TEORIJE ISTINE}

Predstavljanje semantičke teorije istine Tarskog moramo započeti preciznijim pojašnjenjm pojma semantike u datom kontekstu. Ovaj pojam, poreklom vezan za filologiju, zadobija svoju logičku upotrebu kod Karnapa (Rudolf Karnap), čiji rad smatramo za predudar radu Tarskog. ${ }^{7}$ Naime, formalnu i pravilima konstituisanu prirodu savremene logike, o kojoj smo prethodno govorili, Karnap označava pojmom logičke sintakse, koju sam naglašeno razvija u duhu teze o logičkoj strukturi svih iskaza - pa i iskaza prirodnih jezika, te u njima formiranih iskaza nauka $i$ filozofije. U pitanju je ideja koju, kako smo videli, možemo pratiti sve do Fregeove ideje o otvorenom jeziku, a otuda i do Raselovog logičkog atomizma i njegovog preobražaja kod ranog Vitgenštajna (Ludwig Wittgenstein). Veza formalne logike i prirodnog jezika sa njegovim semantičkim sadržajima, dakle, nije bila van vidokruga savremene logike. Razlika u pristupu ovom pitanju u odnosu na tradiciju oličena je u odbijanju da se ta logička struktura iskaza prirodnog jezika izvodi na

\footnotetext{
${ }^{7}$ Karnapova sintaksa je zapravo ono što bi se danas zvalo semantikom, a Karnap je razvija nezavisno od Tarskog. Up. Creath, R., 'Carnap's Move to Semantcs: Gains and Losses', in: J. Wolenski, E. Köhler, (eds.), Alfted Tarski and the Vienna Circle. Austro-Polish Connections in Logical Empiricism, Springer, Dordrecht, 1999, str. 66, 70.
} 
osnovu prirodnog jezika i njegovih gramatičkih pravila. Otuda je, kako smo i naglasili, veza formalnog sistema i prirodnog jezika postavljena tako da logički primat ide u korist ovog prvog; navedeno će biti slučaj i kod Tarskog, ali uz zaokret koji ćemo uskoro detaljnije predstaviti.

Pojam semantike se, dakle, u okvirima savremene logike tiče značenja koja zatičemo u formalnim jezicima, vezano za njihove izraze. Budući da sada govorimo o logičkom, a ne o filološkom pojmu semantike, isti, dakle, ne možemo prosto redukovati na značenja reči i izraza, kakva, na primer, zatičemo u rečnicima. Naprotiv, logički pojam semantike neposredno je vezan za pojam istine, koja se i sama shvata u logičkom smislu. ${ }^{8}$

Jednostavnije rečeno, vezu logičkih pojmova istine i semantike bi trebalo razumeti u svetlu postavljanja pitanja o smislenosti određenog iskaza. Naime, ukoliko neki iskaz za nas ima smisla, ukoliko nam je smislen, to znači da je moguće - bar načelno i u nekom predvidivom konačnom broju koraka - utvrditi njegovu istinosnu vrednost, odnosno da je moguće utvrditi da li je on istinit ili ne. Ili, drugačije rečeno, ukoliko za neki iskaz možemo utvrditi da li je istinit ili ne, to znači da je taj iskaz za nas smislen. Važi i obrnuto: ukoliko nismo sigurni kako bismo utvrdili da li je neki iskaz istinit ili ne, ne možemo ga smatrati smislenim. Razmotrimo, na primer, slučaj iskaza Taketa i maluma su isto što $i$ špend vrcle sa štafet-mufticama: pošto nismo sigurni šta ovaj iskaz zapravo znači i tvrdi, odnosno pošto on za nas nema smisla, nemoguće je utvrditi da li je on istinit ili ne; navedeno jasno pokazuje vezu smislenosti i istinitosti. Shodno tome, semantička teorija istine bi podrazumevala tematsko ispitivanje uslova pod kojima se iskazi pojavljuju kao smisleni, odnosno uslova pod kojima iskazi imaju istinosnu vrednost. ${ }^{9}$

Kako vidimo, ovakav pojam semantike u vezi sa istinom ima svoje poreklo u tezama ranog Vitgenštajna, ali možda i više u onima

\footnotetext{
8 Up. Дошен, К., Основна логика, 2013, str. $38 . \quad$ Vidi: http://www.mi.sanu.ac.rs/ kosta/Osnovna\%20logika.pdf (datum pristupa: 29.06.2020.)

9 Up. Kempson, R. M., Semantic Theory, Cambridge University Press, Cambridge, 1999, str. 23.
} 
Bečkog kruga ${ }^{10} \mathrm{U}$ oba slučaja pitanje smislenosti i besmislenosti iskaza bilo je jedno od odlučujućih, te su tako pripadnici Bečkog kruga, inspirisani Vitgenštajnom, tvrdili da smisleni mogu biti samo a) iskazi formalnih nauka (matematike i logike), čija se istinitost utvrđuje spram formalnih pravila sistema kojima pripadaju (logička istinitost, o kojoj smo prethodno govorili), te 2) iskazi empirijskog sadržaja, čija se istinitost određuje verifikacijom na osnovu čulnog opažanja; kao što je poznato, Vitgenštajn je odrekao smislenost iskazima formalnih nauka. U oba slučaja, iskazi tradicionalne metafizike, (normativne) etike i estetike pokazuju se besmislenima, usled nemogućnosti da se verifikuju na bilo koji od pomenutih načina. Isto tako, u oba slučaja, kako možemo primetiti, smislenost i besmislenost iskaza neposredno je vezana za mogućnost utvrđivanja njihove istinitosti.

Doprinos Tarskog ovoj liniji mišljenja sastoji se u tematskom reflektovanju navedenog postupka u užem kontekstu logike, odnosno u tematskom logičkom ispitivanju uslova pod kojima bi iskazi mogli da budu smisleni, to jest, istiniti. ${ }^{11}$ Zanimljivo je da se, pri tome, Tarski odlučuje na jedan sasvim nepretenciozan postupak, na analizu tradicionalne koncepcije logičke istine - one Aristotelove, na osnovu koje dalje izvodi i svoje teze. ${ }^{12}$ Izbor Tarskog pada na Aristotela iz dva razloga: najpre, zbog toga što je Aristotel osnivač logike, te time i onaj čiji su stavovi odredili njen dalji razvoj, a potom i zbog toga što je, prema Tarskom, Aristotelova definicija istine oslobođena kasnijih učitavanja poreklom iz vanlogičkih okvira.

Tarski, dakle, započinje analizom Aristotelove definicije istine: „Tvrditi da nije ono što jest ili da jeste ono što nije jest lažno, a tvrditi da

${ }^{10}$ Up. Schurz, G., 'Tarski and Carnap on Logical Truth - or: What Is Genuine Logic?', in: J. Wolenski, E. Köhler, (eds.), Alfred Tarski and the Vienna Circle. Austro-Polish Connections in Logical Empiricism, Springer, Dordrecht, 1999, str. 78.

${ }^{11}$ Pri tome, Tarski, izgleda, jednako cilja i na logički i na vanlogički pojam istine. Up. Simons, P., 'Bolzano, Tarski and the Limits of Logic', str. 17.

${ }^{12}$ Up. Tarski, A., 'The Concept of Truth in Formalized Languages', in: Logic, Semantics, Metamathematics. Papers from 1923 to 1938, Clarendon Press, Oxford, 1956, str. 155. 
jest ono što jest ili da nije ono što nije istinito je". ${ }^{13}$ Tarski, potom, pokušava da dati kriterijum primeni na neki konkretni slučaj. Tako on bira iskaz Sneg je beo, te pita pod kojim uslovima bismo smatrali da je taj iskaz tačan; naravno, bez mnogo komplikacija on zaključuje da bi to bio slučaj ukoliko bi sneg zaista bio beo. ${ }^{14} \mathrm{U}$ ovom delu argumentacije Tarski ne odstupa bitno od Aristotela, kao ni od tradicije, ali ni od naših prirodnih intuicija, na koje on delom i računa. Sledeći korak, na prvi pogled, deluje jednako jednostavno i intuitivno, ali upravo on je odlučujući za pomeranje koje će u ovom pogledu Tarski načiniti.

Naime, na osnovu prethodnog, Tarski zaokružuje svoju analizu, te tvrdi: Iskaz „Sneg je beo" istinit je ako i samo ako je sneg beo. Ovo tvrđenje, u svom prvom sloju, predstavlja samo sumiranje rezultata primene Aristotelove definicije istine na slučaj iskaza Sneg je beo. Međutim, u svom drugom i odlučujućem sloju, ovaj iskaz zapravo je i primer iskaza o uslovima istinosti nekog (datog) iskaza, $\mathrm{i}$ - kao takav on postaje poligon daljeg teorijskog razmatranja o uslovima istinosti iskaza načelno.

Kako vidimo, iskaz Iskaz „Sneg je beo” istinit je ako i samo ako je sneg beo zapravo govori o tome pod kojim uslovima je istinit iskaz Sneg je beo. Pošto ga smatramo istinitim, onda se on može uzeti kao primer čijom ćemo analizom utvrditi uslove istinitosti iskaza načelno, a ne samo u datom slučaju. Po pretpostavci, razlog zbog kog ovaj iskaz smatramo istinitim je u tome što on ispravno detektuje uslove istinitosti iskaza Sneg je beo, a oni, opet, nisu ograničeni na taj konkretni sneg ili njegovu belinu. Jednostavnije rečeno, naš ogledni iskaz mogli bismo poopštiti tako da važi za sve slučajeve, i onda bi on mogao da glasi ovako: Iskaz , ,x” istinit je ako i samo ako $x .{ }^{15}$

Dalju analizu ovog odlikovanog i oglednog primera Tarski provodi naglašavanjem dva njegova posve očigledna i samorazumljiva aspekta. Prvo, oslanjajući se na to da ovaj iskaz smatramo istinitim, Tarski se posvećuje preciznijoj analizi njegovog sadržaja. Šta, zapravo,

\footnotetext{
${ }^{13}$ Aristotel, Metafizika (1011b25), str. 141-142.

${ }^{14}$ Up. Tarski, A., 'The Concept of Truth in Formalized Languages', str. 156.

${ }^{15}$ Up. Ibid., str. 155-156; Kempson, R. M., Semantic Theory, str. 24.
} 
tvrdi iskaz Iskaz „Sneg je beo” istinit je ako i samo ako je sneg beo? $\mathrm{Na}$ prvi pogled, on tvrdi da će iskaz Sneg je beo biti istinit ako i samo ako je realni sneg u realnom svetu zaista beo. Međutim, Tarski nam skreće pažnju na to da su u datom slučaju u vezu dovedena dva dela istog iskaza, a ne iskaz Sneg je beo i materijalna stvar sneg sa njegovom belinom. Ukoliko pažljivije analiziramo naš iskaz, uvidećemo sledeće: on povezuje deo «,,Sneg je beo"» i deo «sneg je beo» - Iskaz, ,Sneg je beo" istinit je ako $i$ samo ako sneg je beo. ${ }^{16}$ Kriterijum istinitosti iskaza koji smo prethodno usvojili, dakle, ne povezuje dva međusobno različita elementa, iskaz i sneg, već dva elementa istog (jezičkog) karaktera.

Tako se ispostavlja da se naš kriterijum istine i sam nalazi izložen u jeziku i zatvoren unutar njegovih okvira. Usvojene interpretacije Aristotela i teze tradicionalne logike nam, nesumnjivo, sugerišu suprotno, ali podrobnija logička analiza Aristotelove definicije istine i njene primene na konkretan slučaj, smatra Tarski, pokazuje njihovu manjkavost. Aristotelova definicija, tvrdi on, samom svojom formulacijom izbegava konotacije koje uključuju neke njene kasnije reformulacije, poput adequatio rei et intellectus, a koje impliciraju da je istina situirana u odnos jezika/mišljenja i stvarnosti. Nasuprot tome, prethodna analiza pokazuje da je definicija istine ograničena na okvire jezika i da ne smera van njih.

Konačno, Tarski ovo smatra veoma važnim, jer tek zbog toga mi uopšte možemo govoriti o mogućnosti da se ponudi logička definicija istine iskaza: pošto je kriterijum istine zatvoren na okvire jezika, a jezik je domen logičkih analiza i važenja logičkih pravila, onda je moguće logički analizirati jezik i logički ustanoviti kriterijum istine koji unutar njega važi. U suprotnom, to ne bi bilo moguće, pošto bi uslov istine prevazilazio okvire u kojima se kreće logika i prešao na stranu metafizike: istina bi, tako, zavisila od realnosti (u datom slučaju od snega), te se ne bi ni mogla logički ustanoviti (jer sneg ne pokazuje interes za logiku).

${ }^{16}$ Ovde smo izmenili prirodnu strukturu rečenice radi jasnijeg uviđanja poente Tarskog. 
Jednostavnije rečeno, Tarski pokazuje da je u tradicionalnim okvirima načinjena greška. Naime, čini se da tvrđenjem da istinitost iskaza zavisi od stanja stvari u realnosti impliciramo da je upravo ono stanje stvari u realnosti - uslov istinitosti iskaza. $\mathrm{Na}$ delu je, međutim, nešto sasvim drugačije: ovim tvrđenjem mi zapravo tvrdimo da istinitost iskaza zavisi od onoga što mi mislimo da jeste stanje stvari u realnosti, to jest, da mi dati iskaz sameravamo spram sopstvenog viđenja $i$ razumevanja stvarnosti, datih nam putem opažanja, razumske obrade opažaja i slično. U neku ruku, tradicija je pomešala naš sud o stvarnosti i stvarnost samu, usled čega je i tvrdila ovaj objektivni kriterijum istine; primer koji bi mogao da ilustruje poentu Tarskog je Lokova (John Locke) definicija znanja kao slaganja ideja.

Ovako postavljeno razumevanje kriterijuma i definicije istine dalje povlači i drugi krak analize kod Tarskog, koji se odnosi na drugu samorazumljivu pretpostavku o našem oglednom iskazu, a rezultira pozitivnim tezama semantičke teorije istine Tarskog. Naime, kako smo videli, unutar jednog iskaza - Iskaz „Sneg je beo” istinit je ako i samo ako je sneg beo - detektovali smo dva njegova ključna dela «,Sneg je beo"» i «sneg je beo». Na prvi pogled, pošto su ovo dva dela istog iskaza, deluje da se oni jedan od drugog ne razlikuju bitno, odnosno da su oni isti po svom karakteru. To, međutim, nije slučaj: Tarski utvrđuje da ovde na delu imamo dva različita nivoa jezika, objekt-jezik - jezik o kome se govori («,Sneg je beo"») i meta-jezik - jezik kojim se govori o objektjeziku («sneg je beo»). Zapravo, ako bismo bili iscrpni, morali bismo zaključiti da u meta-jezik spadaju svi sledeći delovi našeg oglednog iskaza: «Iskaz», «istinit je», «ako i samo ako» i «sneg je beo», dok je samo deo «,Sneg je beo"» objekt-jezik, jezik o kome se govori.

Jezik, dakle, nije bez svoje unutrašnje strukture, o čemu nam svedoči i činjenica da smo mi u stanju da jezik koristimo kako bismo govorili o jeziku samom, kako bismo govorili o jeziku kojim govorimo. $\mathrm{Na}$ toj mogućnosti, očigledno, počiva filologija, kao i bilo koje istraživanje jezika, pa samim tim i logika. Ipak, ako je tako, mi onda moramo razlikovati ove dve ravni jezika, objekt-jezik i meta-jezik, te se moramo upitati kome od njih zapravo pripada pitanje o uslovima istinosti naših iskaza. Iz svega prethodno rečenog jasno je da ono pripada ravni 
meta-jezika, odnosno da se prilikom utvrđivanja kriterijuma istinosti iskaza krećemo u domenu govora o iskazima, koji su i sami određene jezičke formacije. Pošto ovde (jezikom) govorimo o jeziku (iskazima), onda je naše pitanje vezano za meta-jezik.

Štaviše, moglo bi se reći da za Tarskog celokupna logika pripada meta-jezičkoj ravni, iako se jedna na drugu ne mogu svesti. Tarski, naime, razlikuje nekoliko elemenata meta-jezika: kako smo videli, on nužno sadrži uže logičke izraze, poput «ako i samo ako», kao i izraze strukturno-deskriptivnog karaktera, poput «iskaz», «istinito je» i slično. ${ }^{17}$ Naročito je zanimljivo da meta-jezik sadrži i imena izraza objekt-jezika; u našem primeru to je «,Sneg je beo"». ${ }^{18}$ Dakle, sada možemo ispraviti naše prethodno tvrđenje: svi izrazi iskaza Iskaz „Sneg je beo” istinit je ako i samo ako je sneg beo su meta-jezičkog karaktera, odnosno ovo je (u celini) jedan meta-jezički iskaz. Izraz «,Sneg je beo"» predstavlja metajezički indeks za iskaz objekt-jezika o kome se govori: on sam nije objekt-jezik, jer ne stoji samostalno u odnosu na meta-jezički kontekst $\mathrm{u}$ kom se zatiče, ali on ima specifičnu funkciju zastupanja iskaza objektjezika u tom meta-jezičkom kontekstu, te direktno i upućuje na objektjezik.

Primer će ovo pojasniti. Razmotrimo dva iskaza: 1) Sneg je beo i 2) Iskaz „Sneg je beo” istinit je ako i samo ako je sneg beo. Prvi od njih je iskaz objekt-jezika, dok je drugi iskaz meta-jezika, i to takav da govori o prethodnom primeru iskaza objekt-jezika. U drugom iskazu - dakle, iskazu meta-jezika - prvi se ne pojavljuje direktno, već putem svog zastupnika, koji je jasno naglašen znakovima navoda: ne pišemo Iskaz Sneg je beo istinit je ako i samo ako je sneg beo, već Iskaz „Sneg je beo” istinit je ako i samo ako je sneg beo. Znakovi navoda, tako, ukazuju da ovde nemamo iskaz objekt-jezika, već njegov meta-jezički indeks, njegovog meta-jezičkog zastupnika.

Kako vidimo, semantička teorija istine Tarskog zasnovana je na mogućnosti da se jezik koristi za istraživanje i opisivanje samog jezika, za razlikovanje objekt-jezika i meta-jezika. Odrednice objekt-jezika i

\footnotetext{
${ }^{17}$ Up. Tarski, A., 'The Concept of Truth in Formalized Languages', str. 171-173.

${ }^{18}$ Up. Ibid., str. 157, 159.
} 
meta-jezika ovde ne treba shvatiti apsolutno, već relativno: svaki iskaz koji se razmatra ima status objekt-iskaza, te svaki iskaz kojim se on komentariše zadobija status meta-iskaza. Shodno tome, meta-iskaz koji smo mi prethodno razmatrali može, ukoliko želimo da ga preispitamo u pogledu njegovih uslova istinitosti, postati objekt-iskaz tog novog istraživanja, te bi se za njega, onda, dalje morao konstruisati novi metaiskaz. U tom smislu teorija Tarskog ne podrazumeva umnožavanje ovih meta-jezičkih instanci, već sugeriše samo navedena dva nivoa jezika, koje razlikujemo na svakom od slučajeva analize; Tarski, dakle, ne predviđa beskonačno umnožavanje hijerarhijske strukture jezika po principu metameta-meta-meta-meta... Navedeno je vezano i za njegov otpor prema apsolutnom pojmu istine, koji Tarski, izgleda, razume spram Bolcanovih (Bernard Bolzano) pozicija. ${ }^{19}$

Činjenica da utvrđivanje kriterijuma istinosti iskaza pripada meta-jeziku, te da se logika sada situira u meta-jezičku ravan, bitno menja i način na koji možemo razumeti kako logiku, tako i za nju ključni pojam istine. Uprkos našim prethodnim primerima, teorija Tarskog prevashodno je usmerena na formalne jezike, odnosno na logički kontekst, iako se ona sada već uobičajeno, prema Dejvidsonovoj (Donald Davidson) sugestiji, uzima i kao osnov teorije značenja prirodnih jezika. ${ }^{20} \mathrm{Na}$ ovom mestu nismo u prilici da ponudimo pregled kritika poduhvata Tarskog, uključujući i onu Dejvidsonovu, kao ni detaljniju analizu primene teorije Tarskog istine $\mathrm{u}$ formalnim kontekstima. ${ }^{21}$ Ipak, naša razmatranja zaključićemo komentarom nekih od centralnih ideja ove teorije.

\section{ZAKLJUČNA RAZMATRANJA}

Naša prethodna razmatranja semantičke teorije istine Tarskog zaključujemo komentarom smisla projekta Tarskog i namere koja stoji iza njega. Tarski je, naime, semantičku teoriju istine razvio kao odgovor na

\footnotetext{
${ }^{19}$ Up. Simons, P., 'Bolzano, Tarski and the Limits of Logic', str. 14-15.

${ }^{20}$ Up. Kempson, R. M., Semantic Theory, str. 23.

21 Up. Davidson, D., Truth and Predication, Harvard University Press, Cambridge, 2005, str. 15-28; Putnam, H., 'A Comparison of Something with Something Else', New Literary History, Vol. 17, No. 1, 1985, str. 61-79.
} 
probleme koji su se s obzirom na pojam istine javljali u savremenoj logici, istovremeno ubeđen u značaj ovog pojma za logiku i nauke načelno. Gedelove teoreme nepotpunosti, možda više nego Raselov paradoks, pokazuju ovu problemsku situaciju: pomenuti primat pojma dokazivosti u odnosu na pojam istinitosti kod Gedela izveden je upravo stoga što je Gedela upotreba pojma istine vodila u paradokse. Tarski, dakle, želi da izgradi takvu teoriju istine koja bi opravdala njen značajan status u okvirima logike, a koja ne bi vodila u paradokse, smatrajući da je to prihvatljivija opcija nego napuštanje pojma istine usled problema kojima on vodi.

Kako smo videli, Tarski svoj cilj ostvaruje uz uvažavanje pouka stečenih u logici putem Raselovog paradoksa, odnosno on zaobilazi autoreferencijalnost jezika koja bi vodila u paradokse uvodeći strukturnu razliku objekt-jezika i meta-jezika. Navedeno, zapravo, znači da se kriterijum istinitosti iskaza uvek mora iznova ustanovljavati od slučaja do slučaja, kao i da meta-jezik mora biti ekspresivniji, odnosno bogatiji u pogledu ekspresivnosti od objekt-jezika. ${ }^{22}$ Ukoliko bismo, kao što je ranije pomenuto, želeli da postavimo pitanje kriterijuma istinitosti za naš meta-jezički iskaz Iskaz „Sneg je beo" istinit je ako i samo ako je sneg beo, morali bismo da ga tretiramo kao objekt-iskaz i da za njega konstruišemo novi meta-iskaz, recimo: Iskaz 'Iskaz „Sneg je beo” istinit je ako i samo ako je sneg beo' istinit je ako i samo ako (važi) iskaz „Sneg je beo" istinit je ako i samo ako je sneg beo. ${ }^{23}$

Takav meta-iskaz očigledno je kompleksniji od onoga koji smo mi analizirali, te bi zahtevao i posebnu obradu. Ipak, ono što je za nas ovde važno je da se u navedenim slučajevima, ali i u svim slučajevima ovog tipa načelno, primenjuje ista ideja: uslovi istinitosti određenog iskaza moraju se ustanoviti njegovom logičkom analizom, koja će se kretati u meta-jeziku (koji za tu potrebu konstruišemo), te koja će, samim tim, uvek izbegavati paradoks autoreferencije raselovskog tipa. ${ }^{24}$ Drugim

\footnotetext{
${ }^{22}$ Up. McGee, V., Truth, Vagueness, and Paradox, str. 67-68.

${ }^{23}$ Up. Tarski, A., 'The Concept of Truth in Formalized Languages', str. 195.

${ }^{24}$ Up. Levison, A. B., 'Logic, Language, and Consistency in Tarski's Theory of Truth', Philosophy and Phenomenological Research, Vol. 25, No. 3, 1965, str. 390-391.
} 
rečima, kada je reč o uslovima istinosti iskaza, logika ne barata i ne može da barata sa nekim unapred datim, jednoznačnim i nepromenljivim kriterijumom ili definicijom istine. ${ }^{25}$ Naprotiv, ona barata samo logičkim postupcima analize, koji će, ukoliko se adekvatno primenjuju, ponuditi takav kriterijum s obzirom na dati slučaj, odnosno kontekstualnoosetljivo. $^{26}$ Kontekstualna osetljivost, međutim, ovde ne znači $i$ proizvoljnost ili relativnost istinitosti i njenog kriterijuma, jer se ovde radi isključivo o logičkim kontekstima, a ne o subjektivnim preferencijama. Upravo stoga je semantička teorija istine mogla biti toliko značajna za razvoj logike mogućih svetova, odnosno za razvoj savremene modalne logike.

Pitanje odnosa sintaksičkog, odnosno formalno-simboličkog karaktera savremene logike i njene veze sa prirodnim jezicima se, kako vidimo, ovim takođe značajno menja. Zadržavajući svoj karakter, logička analiza sada se intimnije povezuje sa prirodnim jezicima i njima pripadnom semantikom (koja se razlikuje od ove logičke), postajući tako fleksibilnija i više usmerena na operacije nego na strukturne opise logičkih osnova prirodnog jezika. Umesto da, prema Fregeovom modelu, logika samo nudi formu koju dalje treba popuniti vanlogičkim sadržajima, ili da, po Raselovoj sugestiji, ona treba da zađe u strukturu prirodnog jezika, izvlačeći iz nje logički značajne elemente i odnose, nakon Tarskog logika je u prilici da ponudi logički koherentan opis veze logičkih i vanlogičkih elemenata jezičke prakse, a time i da uvaži specifičnosti prirodnih jezika.

Ovakva mogućnost, smatra Tarski, bila je zaprečena mnogobrojnim problemima u dotadašnjim pokušajima povezivanja uže logičke i semantičke prirode jezika, kakvi su, na primer, očigledni i u neformalnim paradoksima, poput paradoksa lažova, koji pominje i sam Tarski. Tarski, naime, kao ključne u tom pogledu izdvaja dve pretpostavke kojima su se rukovodili dotadašnji pristupi logičkoj analizi prirodnih jezika. ${ }^{27}$ Prva od njih je pretpostavka da osnovni zakoni logike

\footnotetext{
${ }^{25}$ Up. Ibid., str. 386.

${ }^{26}$ Up. Tarski, A., 'The Concept of Truth in Formalized Languages', str. 159.

${ }^{27}$ Up. Ibid., str. 164-165.
} 
važe i u prirodnim jezicima; pretpostavka koja je, kako smo videli, karakteristična i za Aristotela (i tradiciju), i za očeve osnivače savremene logike. Druga od njih je, međutim, pretpostavka semantičke univerzalnosti, odnosno semantičke zatvorenosti jezika: teza prema kojoj jezik sadrži i izraze za sopstvene izraze, uključujući tu i semantičke termine kojima se jednako povratno referira na izraze samog tog jezika (poput istinito).$^{28}$ Jednostavnije rečeno, teza semantičke univerzalnosti tvrdi da se jezikom mogu izraziti i pravila koja određuju upotrebu samog tog jezika, te je u tom smislu jezik semantički zatvoren.

Tarski, dakle, smatra da ove dve pretpostavke o jeziku ne mogu biti istovremeno prihvaćene, a da to ne vodi u paradokse; u tom smislu, jedna od njih morala bi se odbaciti, ukoliko paradokse želimo da izbegnemo. Razmotrimo primer paradoksa lažova: ukoliko ja kažem $J a$ lažem, taj iskaz, kojim ja očigledno govorim o sopstvenom govorenju, uzet sam po sebi, nije formalni paradoks. On je potpuno razumljiv i ne tvrdi eksplicitno dve međusobno isključive teze; naprotiv, ovim iskazom tvrdi se samo jedna teza, odnosno ta da ja lažem. Ipak, kada razmotrimo logičke posledice datog iskaza, on se pokazuje kao paradoksalan: 1) ako govorim istinu kada ga tvrdim, to znači da lažem, odnosno da ne govorim istinu, a 2) ako lažem kada ga tvrdim, to znači da nije tačno da ja lažem, što znači da govorim istinu, što znači da ne lažem kada tvrdim dati iskaz. Ukratko, paradoks se pojavljuje tek kada od iskaza koji je semantički univerzalan (iskaz unutar jezika o samom tom jeziku) zahtevam da bude u skladu sa zakonima logike.

U tom smislu, kako je već navedeno, moramo napustiti jednu od pretpostavki - ili jezik nije semantički univerzalan, ili unutar njega ne važe pravila logike. Tarski, kako smo videli, odlučuje da napusti pretpostavku semantičke univerzalnosti, ili - bolje rečeno - odlučuje da napusti jaku tezu o semantičkoj univerzalnosti. Naime, on je nesumnjivo stava da prirodni jezici jesu semantički univerzalni, u smislu da se unutar tih jezika mogu formulisati iskazi o samom tom jeziku i njegovom funkcionisanju, što i sami možemo potvrditi. Sa druge strane, pošto ne želi da isključi tezu o važenju logičkih zakona unutar prirodnih jezika,

${ }^{28}$ Up. Ibid., str. 164. 
Tarski zapravo tvrdi sledeće: prirodni jezici imaju mogućnost da formulišu iskaze o samom tom jeziku (slaba semantička univerzalnost), ali ukoliko formulišu takve iskaze koji se tiču semantike tog jezika, odnosno logičkih pravila pod kojima on funkcioniše (jaka semantička univerzalnost), to će neminovno voditi paradoksima. Shodno tome, Tarski odbacuje jaku tezu semantičke univerzalnosti i uvodi hijerarhiju meta-jezika i objekt-jezika: kako smo videli, semantička pravila - poput definicije istine - formulišu se u okvirima meta-jezika, a važe za objektjezik.

Semantičku teoriju istine Tarskog, tako, možemo razumeti kao odlikovani primer za njega karakterističnog stava, koji najjednostavnije možemo predstaviti rečima Pitera Simonsa (Peter Simons), koji tvrdi da Tarski prosto nije bio siguran šta je zapravo logika. ${ }^{29}$ Iako ovo tvrđenje na prvi pogled može da iznenadi, mi ga smatramo ključnim ne samo za Tarskog, već za savremenu logiku uopšte: za razliku od tradicionalne, savremenu logiku odlikuje izvanredna fleksiblinost, kao i kontinuirana otvorenost svih za nju centralnih mislilaca - otvorenost koja se posebno očituje u spremnosti da se već usvojeni fundamenti logike iznova i iznova preispituju, te da se, samim tim, pitanje njenog smisla i karaktera iznova postavlja. Čini se da je Tarski, sa svojom metalogikom i metamatematikom, autor u čijem se delu navedene odlike savremene logike naročito dobro mogu videti.

\section{LITERATURA}

Aristotel, Organon, Kultura, Beograd, 1965.

Aristotel, Metafizika, Paideia, Beograd, 2007.

Creath, R., 'Carnap's Move to Semantcs: Gains and Losses', in: J. Wolenski, E. Köhler, (eds.), Alfred Tarski and the Vienna Circle. Austro-Polish Connections in Logical Empiricism, Springer, Dordrecht, 1999.

Davidson, D., Truth and Predication, Harvard University Press, Cambridge, 2005.

${ }^{29}$ Up. Simons, P., 'Bolzano, Tarski and the Limits of Logic', str. 13. 
Дошен, К., Основна логика, 2013. Elektronsko izdanje, slobodno na internetu: http://www.mi.sanu.ac.rs/ kosta/Osnovna\%20logika.pdf (datum pristupa: 29.06.2020.)

Kempson, R. M., Semantic Theory, Cambridge University Press, Cambridge, 1999.

Levison, A. B., 'Logic, Language, and Consistency in Tarski's Theory of Truth', Philosophy and Phenomenological Research, Vol. 25, No. 3, 1965.

McGee, V., Truth, Vagueness, and Paradox: An Essay on the Logic of Truth, Hackett Publishing, Indianapolis, 1991.

Putnam, H., 'A Comparison of Something with Something Else', New Literary History, Vol. 17, No. 1, 1985.

Schurz, G., 'Tarski and Carnap on Logical Truth - or: What Is Genuine Logic?', in: J. Wolenski, E. Köhler, (eds.), Alfted Tarski and the Vienna Circle. Austro-Polish Connections in Logical Empiricism, Springer, Dordrecht, 1999.

Simons, P., 'Bolzano, Tarski and the Limits of Logic', in: Philosophy and Logic in Central Europe from Bolzano to Tarski. Selected Essays, Springer, Dordrecht, 1992.

Tarski, A., 'The Concept of Truth in Formalized Languages', in: Logic, Semantics, Metamathematics. Papers from 1923 to 1938, Clarendon Press, Oxford, 1956.

\author{
UNA POPOVIĆ \\ University of Novi Sad, Faculty of Philosophy
}

\title{
TARSKI'S SEMANTIC THEORY OF TRUTH
}

\begin{abstract}
This paper is about Tarski's semantic theory of truth, which is presented as a response to the issue of the relationship between formal an syntactic character of contemporary logic and its application to natural languages, that is, as a comment on the question of the logical character of natural language. I will analyze Tarski's semantic theory of truth against the background of the transformation of meaning and function of the concept of truth that took place in the course of the development of contemporary logic; namely, during its second phase, the concept of truth was gradually given up in
\end{abstract}


the favour of the concept of provability. On the other hand, I will use the analysis of Tarski's ideas to show that his semantic theory of truth was developed with regard to paradoxes which marked the development of contemporary logic.

Keywords: Alfred Tarski, semantic theory of truth, object language, metalanguage, paradoxes

Primljeno: 30.6 .2020$.

Prihvaćeno: 10.9 .2020$. 